\title{
Posterior Screw Fixation in Previously Augmented Vertebrae with Bone Cement : Is It Inapplicable?
}

\author{
Jae Hoo Park, M.D., Chang Il Ju, M.D., Ph.D., Seok Won Kim, M.D., Ph.D. \\ Department of Neurosurgery, Chosun University College of Medicine, Gwangju, Korea
}

Objective : The purpose of this study was to determine the feasibility of screw fixation in previously augmented vertebrae with bone cement. We also investigated the influence of cement distribution pattern on the surgical technique.

Methods : Fourteen patients who required screw fixation at the level of the previous percutaneous vertebroplasty or balloon kyphoplasty were enrolled in this study. The indications for screw fixation in the previously augmented vertebrae with bone cement included delayed complications, such as cement dislodgement, cement leakage with neurologic deficits, and various degenerative spinal diseases, such as spondylolisthesis or foraminal stenosis. Clinical outcomes, including pain scale scores, cement distribution pattern, and procedure-related complications were assessed.

Results : Three patients underwent posterior screw fixation in previously cemented vertebrae due to cement dislodgement or progressive kyphosis. Three patients required posterior screw fixation for cement leakage or displacement of fracture fragments with neurologic deficits. Eight patients underwent posterior screw fixation due to various degenerative spinal diseases. It was possible to insert screws in the previously augmented vertebrae regardless of the cement distribution pattern; however, screw insertion was more difficult and changed directions in the patients with cemented vertebrae exhibiting a solid pattern rather than a trabecular pattern. All patients showed significant improvements in pain compared with the preoperative levels, and no patient experienced neurologic deterioration as seen at the final follow-up.

Conclusion : For patients with vertebrae previously augmented with bone cement, posterior screw fixation is not a contraindication, but is a feasible option.

Key Words : Bone cement · Osteoporosis · Cement augmentation.

\section{INTRODUCTION}

Bone cement augmentation procedures, such as percutaneous vertebroplasty (VP) or balloon kyphoplasty (KP), for osteoporotic compression fractures are simple and minimally invasive. Owing to their simplicity and rapid efficacy, they have been popular for the management of incapacitating pain related to osteoporotic compression fractures ${ }^{4,6)}$.

Nonetheless, complications or delayed sequelae after VP or $\mathrm{KP}$ include leakage of cement into the spinal canal, cement dislodgement or fragmentation, and adjacent vertebral fractures. In such cases, patients usually require posterior screw

- Received : February 16, 2017 •Revised : April 12, 2017 •Accepted : May 11, 20177

- Address for reprints : Seok Won Kim, M.D., Ph.D.

Department of Neurosurgery, Chosun University College of Medicine, 365 Pilmun-daero, Dong-gu, Gwangju 61453, Korea Tel : +82-62-220-3126, Fax : +82-62-227-4575, E-mail : chosunns@chosun.ac.kr

This is an Open Access article distributed under the terms of the Creative Commons Attribution Non-Commercial License (http://creativecommons.org/licenses/by-nc/4.0) which permits unrestricted non-commercial use, distribution, and reproduction in any medium, provided the original work is properly cited. 
fixation for structural stabilization of the augmented vertebrae $^{10)}$. Furthermore, spine surgeons occasionally encounter that posterior screw fixation is indicated in previously augmented vertebrae for degenerative spinal diseases.

Many clinical reports have examined the safety and efficacy of bone cement-augmented screw fixation for the treatment of osteoporotic spines to increase the pull-out strength $\mathrm{h}^{3,5)}$. However, to the best of the authors' knowledge, no previous reports have evaluated the clinical results of posterior screw fixation in previously augmented vertebrae with bone cement for osteoporotic compression fractures.

Screw fixation in previously augmented vertebrae is considered difficult or even a contraindication owing to the excessive reinforcement of stiffness and strength after VP or KP. The purpose of this study was to evaluate the clinical results of screw fixation in previously augmented vertebrae for osteoporotic compression fractures and to determine whether this technique is feasible.

\section{MATERIALS AND METHODS}

From 2010 to 2015, 14 patients (3 men and 11 women) who underwent screw fixation in the vertebrae previously augmented for osteoporotic compression fractures were enrolled in this study. The following were the inclusion criteria : 1) previous VP or KP for an osteoporotic compression fracture, 2) symptom-free period after VP or KP for more than1month, and 3) newly developed mechanical back pain or neurologic deficits requiring posterior screw fixation for structural stabilization.

The study also included revision surgeries for delayed complications of VP or KP, such as cement dislodgement or neurologic deficits due to cement leakage. Degenerative spinal diseases requiring decompression and screw fixation at augmented levels were also included. However, patients with intraoperative complications and late spondylodiscitis requiring an anterior approach were excluded. All procedures were performed by a single surgeon. The augmented vertebral bodies were classified into two groups according to cement distribution pattern on simple radiographs. The criteria were as follows : 1) solid-type vertebral bodies with compact and 2) solid cement filling and trabecular-type vertebral bodies with sponge-like filling cement.

\section{Surgical procedure}

After explanation of the procedure, the patients were anesthetized and placed in the prone position on a radiolucent table. A standard open posterior approach with transpedicular screw fixation was performed in six patients; percutaneous screw fixation was confined to the augmented vertebrae in the other eight patients. All patients were allowed to ambulate in a thoracolumbosacral orthosis brace on postoperative day 2 . Simple radiographs were taken preoperatively and serially and were used to investigate the pattern of previous cement distribution, fusion status, or screw loosening. All pre-VP, pre-KP, and preoperative magnetic resonance images were also obtained and assessed by the authors.

\section{Safety and outcome evaluations}

The patients were evaluated at the final follow-up using the visual analog scale (VAS) and a modified version of MacNab's criteria for characterizing the clinical outcomes after spine surgery. Comparisons at time points were performed using paired t-tests, and differences were considered statistically significant when the $p$-values were $<0.05$.

\section{RESULTS}

A total of 14 patients (3 men and 11 women) underwent screw fixation in the previously augmented vertebrae for osteoporotic compression fractures. Twelve patients underwent VP, and two underwent KP. The mean age of the patients was 74.1 (68-82) years, and the mean follow-up period was 11.5 (6-18) months. Table 1 shows the patient demographics in detail. It was possible to insert screws in the previously augmented vertebrae in all patients. However, the screw trajectory was blocked by the cement in the three patients who showed a solid cleft cement distribution pattern; this necessitated a change from the optimal direction or insertion of a short screw.

Three patients had progressive kyphosis due to cement dislodgement; two of them had intravertebral cleft (IVC) signs and anterior cortical bone destruction in their pre-VP or preKP lateral radiographs. Three patients showed late neurological deterioration after a period of pain relief. Neurological impairment developed insidiously (mean revision time, 3.7 months); the causes of late neurological deterioration were ce- 
Table 1. Demographics of the patients

\begin{tabular}{|c|c|c|c|c|c|c|c|c|c|c|}
\hline $\begin{array}{l}\text { Case } \\
\text { No. }\end{array}$ & Age/sex & BMD & $\begin{array}{l}\text { IVC before } \\
\text { VP or KP }\end{array}$ & Level & VP or KP & $\begin{array}{l}\text { Cement } \\
\text { pattern }\end{array}$ & Cause of revision & $\begin{array}{l}\text { Time to } \\
\text { revision } \\
\text { (months) }\end{array}$ & $\begin{array}{c}\text { Open or } \\
\text { percutaneous }\end{array}$ & Remarks \\
\hline 1 & $81 / F$ & -3.4 & - & L1 & VP & Trabecular & $\begin{array}{l}\text { Bone fragment } \\
\text { displacement }\end{array}$ & 5 & Open & - \\
\hline 2 & $74 / F$ & -3.2 & Yes & L3 & KP & Solid & $\begin{array}{l}\text { Cement } \\
\text { dislodgement }\end{array}$ & 4 & Open & $\begin{array}{l}\text { Short screw for } \\
\text { cement block }\end{array}$ \\
\hline 3 & $69 / F$ & -3.0 & - & $L 2, L 3$ & VP & Solid & Cement leakage & 3 & Open & $\begin{array}{l}\text { Upward direction } \\
\text { for cement } \\
\text { block }\end{array}$ \\
\hline 4 & $82 / F$ & -4.1 & - & L5 & VP & Solid & Spondylolisthesis & 12 & Percutaneous & - \\
\hline 5 & $75 / F$ & -3.0 & - & L3 & VP & Trabecular & Foraminal stenosis & 5 & Percutaneous & - \\
\hline 6 & 69/M & -3.0 & Yes & L1 & VP & Solid & $\begin{array}{l}\text { Cement } \\
\text { dislodgement }\end{array}$ & 4 & Open & $\begin{array}{l}\text { Short screw for } \\
\text { cement block }\end{array}$ \\
\hline 7 & $68 / F$ & -3.0 & - & L2 & $\mathrm{KP}$ & Solid & Cement leakage & 3 & Open & - \\
\hline 8 & $74 / F$ & -3.2 & - & L3 & VP & Trabecular & Spondylolisthesis & 18 & Open & - \\
\hline 9 & $76 / F$ & -3.7 & - & $\llcorner 4$ & VP & Trabecular & Spondylolisthesis & 8 & Percutaneous & - \\
\hline 10 & $73 / F$ & -3.6 & - & L5 & VP & Trabecular & Foraminal stenosis & 10 & Percutaneous & - \\
\hline 11 & $80 / F$ & -3.4 & - & $\llcorner 4$ & VP & Trabecular & Foraminal stenosis & 17 & Percutaneous & - \\
\hline 12 & $68 / F$ & -3.8 & - & L3 & VP & Trabecular & Foraminal stenosis & 7 & Percutaneous & - \\
\hline 13 & 77/M & -3.0 & - & $\llcorner 4$ & VP & Trabecular & Spondylolisthesis & 8 & Percutaneous & - \\
\hline 14 & $72 / \mathrm{M}$ & -2.9 & - & L3 & VP & Trabecular & Spondylolisthesis & 9 & Percutaneous & - \\
\hline
\end{tabular}

BMD : bone mineral densitometry, IVC : intravertebral cleft, VP : vertebroplasty, KP : kyphoplasty, mo : months, F : female, $M$ : male
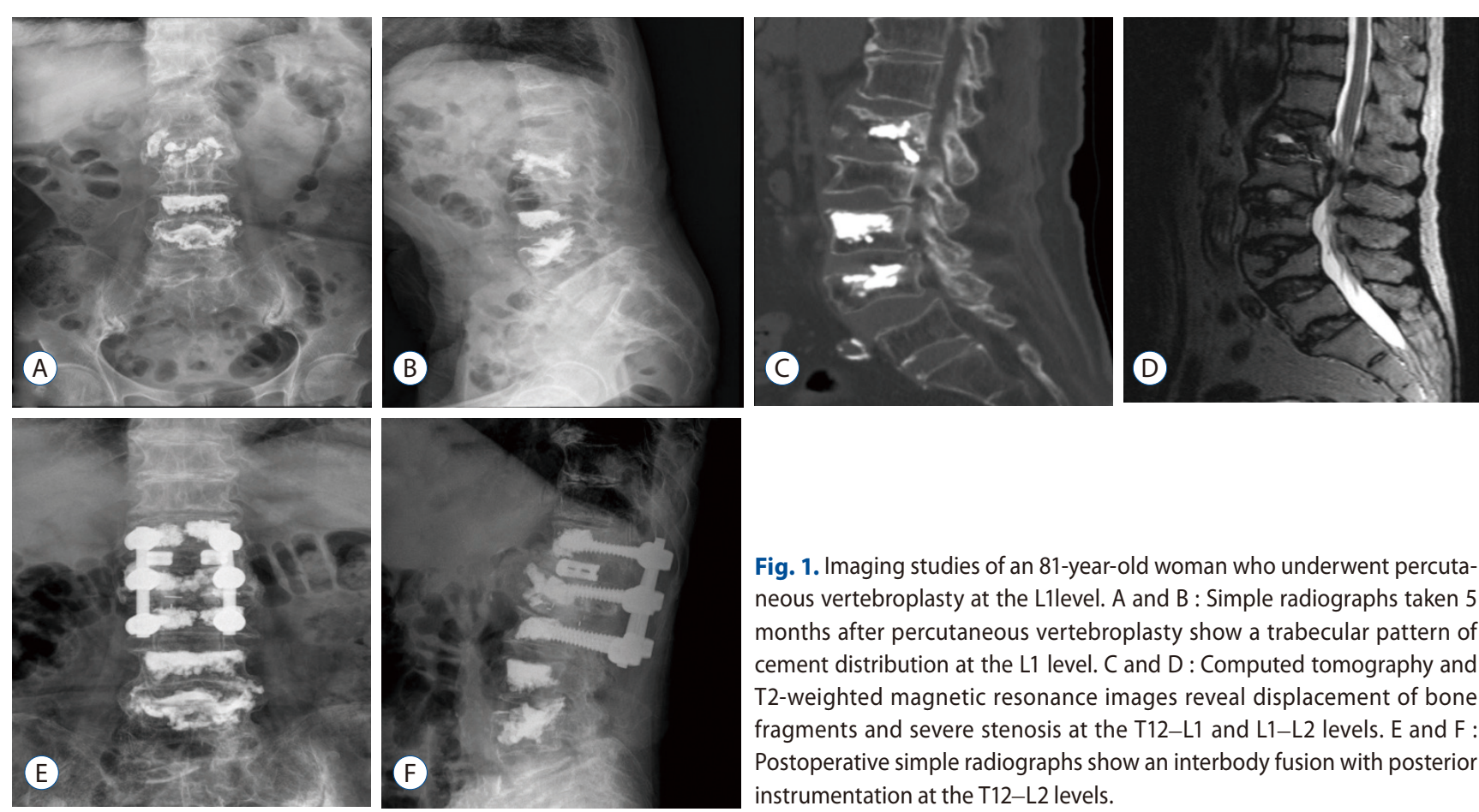

Fig. 1. Imaging studies of an 81-year-old woman who underwent percutaneous vertebroplasty at the L1level. A and B : Simple radiographs taken 5 months after percutaneous vertebroplasty show a trabecular pattern of cement distribution at the L1 level. C and D : Computed tomography and T2-weighted magnetic resonance images reveal displacement of bone fragments and severe stenosis at the $\mathrm{T} 12-\mathrm{L} 1$ and $\mathrm{L} 1-\mathrm{L} 2$ levels. $\mathrm{E}$ and $\mathrm{F}$ : Postoperative simple radiographs show an interbody fusion with posterior instrumentation at the T12-L2 levels. 
ment leakage or displacement of a fracture fragment from the cemented vertebrae. These patients underwent decompression and posterior screw fixation with an interbody fusion. Removal of the fragmented or dislodged cement was possible through the posterior approach (Figs. 1 and 2).

Eight patients underwent posterior screw fixation and interbody fusion for spondylolisthesis or foraminal stenosis at the level of the previously augmented vertebrae. They all underwent percutaneous screw fixation instead of an open transpedicular screw fixation (Fig. 3).

\section{Clinical outcome}

At the final follow-up after surgery, 12 patients (86\%) showed excellent or good outcomes according to the modified MacNab's criteria. Prior to surgery, the mean pain VAS score was 7.9; this decreased to 3.3 at the final follow-up. The improvement was statistically significant $(p<0.05)$. No major complications were observed in any study participant. During the follow-up period, two patients sustained fractures after minor injuries. VP or KP with bone cement augmentation was performed to treat these fractures.

\section{DISCUSSION}

Osteoporotic compression fractures are a common and major cause of morbidity in the elderly. VP and KP with polymethylmethacrylate for osteoporotic compression fractures have gained widespread popularity owing to their rapid effectiveness and simplicity.

In spite of their advantages with good clinical outcomes and simplicity, they also have complications. Excluding acute complications, such as extravasation of cements, pulmonary embolism through the venous drainage system, and hematoma, late
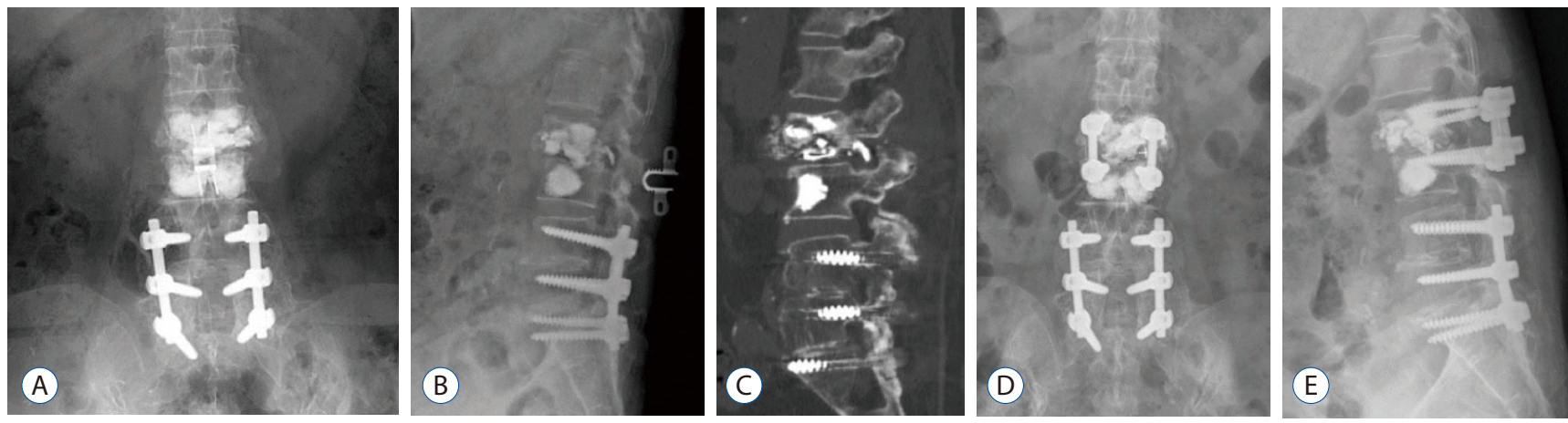

Fig. 2. Imaging studies of a 69 -year-old woman who underwent percutaneous vertebroplasty at the L2 and L3 levels at a local clinic. A and B : Simple radiographs taken 2 months after percutaneous vertebroplasty reveal a solid pattern of cement distribution and cement leakage in the left $L 2$ foramen. C : Computed tomography image shows a more prominent cement leakage. D and E : Postoperative simple radiographs show a complete removal of leaked cement with posterior instrumentation inserted in a superior direction.
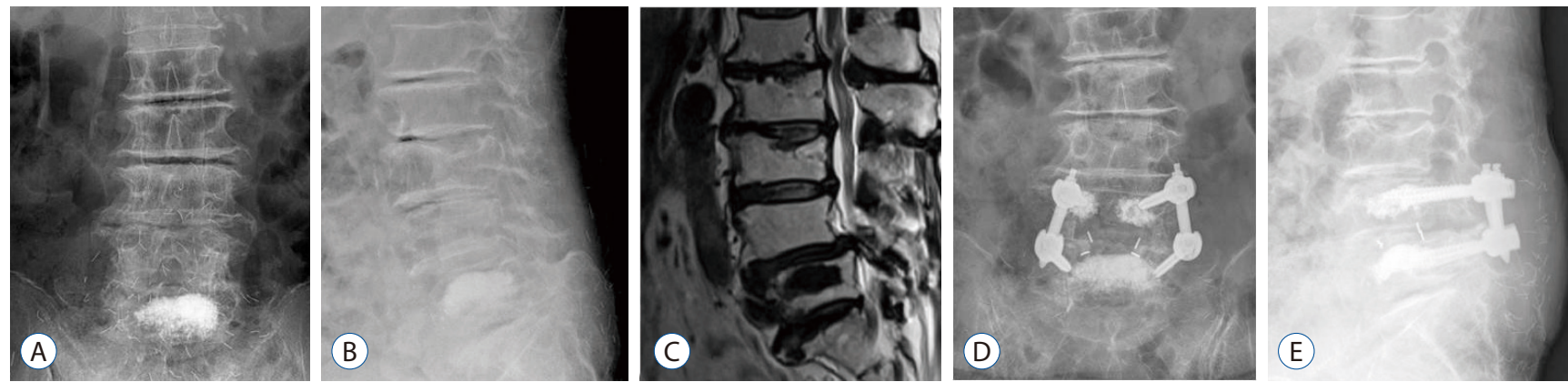

Fig. 3. Imaging studies of an 82-year-old woman who underwent percutaneous vertebroplasty for an L5 osteoporotic compression fracture. A and B : Simple radiographs show a good filling of the bone cement with a solid pattern at the L5 body and spondylolisthesis at the L4-L5 levels. C : Sagittal T2weighted magnetic resonance image reveals severe stenosis at the L4-L5 levels. D and E : Postoperative simple radiographs show an interbody fusion with cages and percutaneous instrumentation. 
clinical complications, such as infection, delayed adjacent segment fractures, and cement displacement following VP or KP may occur ${ }^{8,9)}$. Moreover, spine surgeons sometimes encounter situations requiring surgical treatments of augmented vertebrae for degenerative spinal diseases, such as spondylolisthesis or foraminal stenosis. In such cases, application of rigid posterior instrumentation and decompression is usually required to stabilize the spine. However, whether screws can penetrate abnormally consolidated cement-augmented vertebrae is yet unclear.

It is well known that a larger volume of bone cement may increase the risk of both cement leakage and adjacent fractures because of overstiffening of the segment and less deformation of the vertebral body ${ }^{1)}$. Oka et al. ${ }^{7)}$ also reported that a solid pattern of cement distribution was related to the presence of an IVC and a higher incidence in new compression fractures and is a poor prognostic factor.

In our consecutive series, two patients with IVC showed cement dislodgement and progressive collapse of the augmented vertebral body. They showed a solid pattern of cement distribution with IVC after the initial VP or KP. It is believed that less interdigitation of cements and progressive bone resorption can be the causes of this delayed complication ${ }^{2)}$. Posterior instrumentation using short screws for cement blockage and posterolateral bone fusion without anterior reconstruction were performed in these patients.

A possible delayed complication related to VP or KP is cement leakage into surrounding tissues during the procedure, potentially causing radiculopathy or myelopathy. Moreover, progressive collapse of an augmented vertebral body and displacement of bone fragments can aggravate neurological complications without a history of trivial injury.

In our study, three patients with cement leakage or fragmentation of the bone developed delayed neurologic deficits after a period of symptom relief following augmentation. Posterior decompression of neural elements via removal of the leaked cements or bone fragments with posterior instrumentation and interbody fusion was performed. In one patient who showed a solid pattern of cement distribution following VP with a lack of interspersion along the trabecular spaces, it was more difficult to insert screws through an ideal trajectory. Although the procedure was successful, the bone cement served as an obstacle to the screw insertion, and the screws were inserted in a more superior direction than what was considered ideal.

Posterior screw fixation was performed percutaneously in eight patients for degenerative spinal diseases, such as spondylolisthesis or foraminal stenosis without difficulties. In the present study, we also performed posterior screw fixation in the previously augmented vertebrae with bone cement in revision surgeries for delayed complications following VP or KP and for degenerative spinal diseases. Regardless of whether the screw insertion technique was percutaneous or open, a trabecular cement pattern made it possible to insert screws without difficulties. Although it was difficult to insert screws in an ideal trajectory when the cement distribution showed a solid pattern, the results of our study showed that posterior screw fixation is not a contraindication and can safely be used even in elderly patients.

However, despite our excellent outcomes, this study is intrinsically limited owing to its retrospective review of a heterogeneous patient group. Moreover, since we did not know the exact amount of the injected cement volume, we could not analyze the correlation between the injected cement volume and surgical outcome. Thus, case-controlled studies on delayed complications of bone cement augmentation procedures with long-term follow-ups are crucial.

\section{CONCLUSION}

Posterior screw fixation in the vertebrae previously augmented with bone cement is not a contraindication and can even be used in revision surgeries for delayed complications following VP or KP.

\section{PATIENT CONSENT}

The patient provided written informed consent for the publication and the use of their images.

\section{- Acknowledgements}

The present study was supported by grants from the Clinical Medicine Research In statute at Chosun University Hospital 2016. 


\section{References}

1. Graham J, Ahn C, Hai N, Buch BD : Effect of bone density on vertebral strength and stiffness after percutaneous vertebroplasty. Spine (Phila Pa 1976) 32 : 505-511, 2007

2. Ha KY, Kim YH, Chang DG, Son IN, Kim KW, Kim SE : Causes of late revision surgery after bone cement augmentation in osteoporotic vertebral compression fractures. Asian Spine J 7 : 294-300, 2013

3. Jung HJ, Kim SW, Ju Cl, Kim SH, Kim HS : Bone cement-augmented short segment fixation with percutaneous screws for thoracolumbar burst fractures accompanied by severe osteoporosis. J Korean Neurosurg Soc $52: 353-358,2012$

4. Kim HS, Kim SH, Ju Cl, Kim SW, Lee SM, Shin H : The role of bone cement augmentation in the treatment of chronic symptomatic osteoporotic compression fracture. J Korean Neurosurg Soc 48 : 490-495, 2010

5. Kim HS, Park SK, Joy H, Ryu JK, Kim SW, Ju Cl : Bone cement augmentation of short segment fixation for unstable burst fracture in severe osteoporosis. J Korean Neurosurg Soc 44 : 8-14, 2008

6. Lee K, Lee SG, Kim WK, Yoo CJ, Park CW : Comparison vertebroplasty with kyphoplasty in delayed post-traumatic osteonecrosis of a vertebral body(kummell's disease). Korean J Spine 5 : 70-76, 2008

7. Oka M, Matsusako M, Kobayashi N, Uemura A, Numaguchi $Y$ : Intravertebral cleft sign on fat-suppressed contrast-enhanced MR: correlation with cement distribution pattern on percutaneous vertebroplasty. Acad Radiol 12 : 992-999, 2005

8. Trout AT, Kallmes DF, Lane Jl, Layton KF, Marx WF : Subsequent vertebral fractures after vertebroplasty: association with intraosseous clefts. AJNR Am J Neuroradiol 27 : 1586-1591, 2006

9. Wang HS, Kim HS, Ju Cl, Kim SW : Delayed bone cement displacement following balloon kyphoplasty. J Korean Neurosurg Soc 43 : 212214, 2008

10. Yang SC, Chen WJ, Yu SW, Tu YK, Kao YH, Chung KC : Revision strategies for complications and failure of vertebroplasties. Eur Spine J 17 : 982-988, 2008 